\title{
Correction to: Assessment of energy vulnerability in urban crowded space of Indian Himalaya
}

\author{
Laraib Ahmad $^{1} \cdot$ Mohammad Younus Bhat $^{2} \cdot$ Vishal Singh $^{1}$ \\ Published online: 19 August 2021 \\ (C) Springer-Verlag GmbH Germany, part of Springer Nature 2021
}

\section{Correction to: Environmental Science and Pollution Research https://doi.org/10.1007/s11356-021-15408-x}

1. In the 5th paragraph of the Methodology section, the equation was not presented properly. Some text are missing.

Where wi are weights exposing the relative importance of each component with their significant properties $0<w i<1$ and $w 1+w 2+\cdots+w m=1$. We assume the weights vary inversely as the variation in the respective indicators of vulnerability as follows:

2. Inverted commas are emerging in the initials of some paragraphs while viewing the pdf, which was not present in the proofreading doc. Such as:-

i. Page No. 2, Section. Profile of study area, first para ii. $\operatorname{Pg} 3,1$ st para, in the end

iii. Pg 3, section methodology, 1st para, an inverted comma is present in the initial and end of it.

iv. Pg.5, 2nd para

v. Pg.6, 1st para, in starting and in the end.

vi. Pg. 6, Section Result and Discussion, 1st para, present in the initial and end of it.

vii. Pg6, Section Energy accessibility and affordability, comma is present in the end of para.

The original article has been corrected.

Publisher's note Springer Nature remains neutral with regard to jurisdictional claims in published maps and institutional affiliations.

The online version of the original article can be found at https://doi.org/ 10.1007/s11356-021-15408-x

Laraib Ahmad

laraib@cedarhimalaya.org

Mohammad Younus Bhat

younus.bhat@ddn.upes.ac.in

Vishal Singh

vishal@ cedarhimalaya.org

1 Centre for Ecology Development and Research (CEDAR), Dehradun 248006, India

2 Department of Economics and International Business, School of Business, University of Petroleum and Energy Studies,

Dehradun 248007, India 